\title{
Encoding differences in recognition and recall*
}

\author{
STEPHEN T. CAREY† and ROBERT S. LOCKHART \\ University of Toronto, Toronto M5S IA1, Ontario, Canada
}

\begin{abstract}
After practice consisting of the free recall of five blocked categorized lists, Ss were presented a sixth list and then unexpectedly tested for recognition. After practice at recognition of the same five lists, Ss were unexpectedly tested for recall following presentation of the sixth test. Recognition performance was superior when items were encoded in anticipation of a recognition test. Intracategory serial position functions for Ss anticipating recall tests were different from those anticipating recognition tests regardless of the retention test employed. The role of control processes in recall and recognition testing is discussed.
\end{abstract}

Much research has been directed at isolating differences between recall and recognition processes. Two-process theories (e.g., Kintsch, 1968, 1970) propose that organization has little or no effect upon recognition, since organization facilitates retrieval and retrieval in recognition is assumed to be trivial. Single-process (threshold) theories of recognition and recall (e.g., Postman, Jenkins, \& Postman, 1948) maintain that recognition and recall provide alternative measures of associate strength and that, if organization facilitates recall, it should facilitate recognition. Evidence that organization does facilitate recognition performance (e.g., Mandler \& Borges, 1971; Mandler, 1972 ) is often used to support the single-process viewpoint, or the conclusion that recognition involves a retrieval component that is nontrivial.

A neglected question is whether typical recall-recognition comparisons confound storage differences with retrieval differences. Such storage effects could result from control processes which differ depending on whether the $S$ is anticipating a recall or recognition test. For convenience, we will refer to these control processes, respectively, as recall and recognition "modes of processing" and ask the question of whether these modes differ in any important respect. Insofar as such differences exist, they would constitute a significant factor in any comparison between recognition and recall performance.

Free recall was used in the present investigation, since organization has been widely studied in this paradigm. Furthermore, Ss were given practice at either recognition or recall modes of storage on the premise that if there are different control processes for these tasks, naive Ss must be given the opportunity to develop them. It is assumed that such practice is sufficient for the development of a storage mode optimal for the particular test of retention.

*This research was supported by a National Research Council of Canada Award to the first author and by Research Grant 0355 from the Research Council of Canada to the second author.

$\nmid$ Requests for reprints should be sent to Stephen T. Carey, Department of Psychology, University of Alberta, Edmonton, Alberta, Canada.
In order to assess differences between recognition and recall storage modes, Ss who were given practice with one form of retention test (recognition or free recall) were unexpectedly tested, following final list presentation, by the alternate form of test. Therefore, Ss in the recall mode of storage condition free recalled five different single-trial lists with blocked categories, and Ss in the recognition mode of storage were tested for recognition after each of the same five lists. Following presentation of the sixth list, Ss who had practiced in the recall mode of storage and testing were tested for recognition, while those who had practiced in the recognition mode of storage were tested for free recall. A comparison of recall performance between Trial 5 and Trial 6 was used as an estimate of the difference between recall and recognition storage processes as measured by recall. A comparison between Trial 5 and Trial 6 recognition performance scores estimates the corresponding difference between storage effects when tested by recognition.

Theories which propose that learning depends on organization make different predictions concerning the effect of organization on recognition performance, depending upon whether they are combined with one-process or two-process theories of recall and recognition. If threshold theory is invoked, then studying material in anticipation of recall (as opposed to recognition) can prove only beneficial, whether retention is tested by recognition or recall, since recall instructions increase organization and organization facilitates learning. If the two-process theory of recall is espoused, then storing material under recall task demands should facilitate recall since organization facilitates retrieval. It should not influence recognition, however, because recognition does not involve retrieval. On the other hand, theories which assert the priority of control processes (e.g., Atkinson \& Shiffrin, 1968; Norman \& Rumelhart, 1970) do not make such predictions. Rather, these theories emphasize that what is stored is a function of the task demands. Thus, optimal performance may occur when $S$ activates the appropriate control processes for a given task. This viewpoint would predict maximal performance when the method of test used is that anticipated by S. However, 
these latter predictions have not been supported by previous investigations. First, Freund, Brelsford, and Atkinson (1969) found no difference between recognition performance on material that was stored in anticipation of recall testing and material stored in anticipation of recognition testing in a paired-associate paradigm. Second, Loftus (1971), using a continuous paired-associate paradigm, found that recognition performance was superior when material was stored under conditions of uncertainty of test (mixed mode) than when it was stored in anticipation of a recognition test.

The rationale for using blocked categorized lists in the present study was to predispose $S$ to a type of organization processing which was capable of being analyzed in spite of single-trial presentation. If, indeed, there are differences between recall and recognition modes of processing, it was hypothesized that these differences might be observable from a comparison of intracategory serial position functions for blocked categorized lists. For example, during recognition processing, attempts to discriminate targets from semantically similar lures might seem an effective form of encoding. During recall processing, organization and unitization might benefit more from encoding common attributes among the items. While there is some evidence that intracategory serial position functions for recall mode of storage show probability of recall to vary inversely with intracategory serial position (Wood \& Underwood, 1967), these functions have not been investigated for the recognition mode of processing. If the recognition mode of processing largely involves discrimination learning rather than unitization, then these intracategory serial position functions may be expected to be less steep than those for recall processing.

\section{METHOD}

\section{Subjects}

The Ss were 66 introductory psychology students from the University of Toronto.

\section{Materials}

Stimulus materials consisted of 48 categories of 10 items each, taken from the Battig and Montague (1969) norms. Twelve lists of 40 items were constructed, each list consisting of 8 categories of five exemplars. This permitted 6 lists to be presented to each $S$, with a parallel set of 6 lists, equated for category membership, to be used for lures in the two-alternative forced-choice recognition test ( $2 \mathrm{AFC}$ ). The exemplars from each of the common categories for each of the six pairs of lists were balanced for mean frequency of occurrence. Thus, each set of 6 lists could be interchangeably used for a target set or a distractor set. Each of the 12 blocked categorized lists was randomized 10 times for both category and intracategory sequences. In addition, 10 different randomizations were used of the order in which the 6 lists were presented.

\section{Procedure}

Blocked categorized free recall lists were presented at a $1-\sec$ rate by means of a closed-circuit TV camera focused on a one-word aperture of a selectric typewriter carriage bearing computer-printed lists. A diapilot, reading signals on magnetic tape, activated a solenoid which advanced the carriage with a change time of $100 \mathrm{msec}$. In an adjacent room, Ss in groups, ranging in size from two to four, viewed the presented material on individual TV monitors, separated by soundboard partitions. For each of the first five lists, following list presentation, Ss in all conditions engaged in the multiplication of three-digit numbers exposed on their TV monitors for $1 \mathrm{~min}$. This task was used to eliminate recency effects (Glanzer \& Cunitz, 1966). Then Ss were given either a 2 -min recognition test or were allowed $2 \mathrm{~min}$ for free recall. On the sixth trial, Ss who had been practiced in recall were instructed, following list presentation and $30 \mathrm{sec}$ of multiplication, to perform a $2 \mathrm{AFC}$ recognition test for the list that they had just seen. In all recognition tests, Ss were informed that one of each of the 40 word pairs were from the previous list and that the other word of the pair had not been seen previously in this experiment. They were given $3 \mathrm{sec}$ to indicate whether the "old" item was the left or right member of each pair.

For the recognition storage condition, following each of the first five list presentations and $1 \mathrm{~min}$ of multiplication, Ss were tested by the $2 \mathrm{AFC}$ recognition test. Following the sixth-list presentation and $30 \mathrm{sec}$ of multiplication, these Ss were told to free recall the most recent list.

\section{RESULTS}

An analysis of variance of the first five lists found that for the recognition data there is a slight increase in performance across successive lists amounting to an average increment in probability correct of 0.01 . Despite its negligible magnitude, this effect is significant $[F(4,800)=2.4, p<.05]$. Similarly, there is a small decrement in performance across successive free recall lists averaging 0.02 in the probability of correct recall. Although the magnitude of this effect is again negligible, it does reach statistical significance $[F(4,800)=7.5$, $\mathrm{p}<.01]$. Considering the high degree of precision in the present experiment, such statistical significance is not impressive, and these effects will be considered to have little substantive importance.

In the analysis of the first five lists, both recognition and recall data showed reliable intracategory serial position effects $[F(4,800)=5.0, p<.01$ and $F(4,800)=$ $16.2, p<.01$, respectively, as graphed in Fig. 1]. There was no intracategory Serial Position by List interaction $[F(16,800)=1.1$ and $F(16,800)=1.6$ for recognition and recall, respectively]. Inspection of Fig. 1 also reveals that the intracategory serial position function appears much steeper across serial positions for the recall condition than for the recognition condition.

Figure 2 depicts the probability of recognition across intracategory serial positions for List 5 and List 6 collapsed over categories. The comparison is made between List 5 and List 6 in order that a contrast in performance on a common recognition test can be seen between Ss practiced in either recognition or recall form of encoding. Thus, the difference between the two functions represents a storage difference between recognition processing (List 5) and recall processing 
(List 6) as measured by recognition testing. Analysis of variance of this recognition data showed List 5 to be superior to List $6[F(1,64)=14.6, p<.01]$, the intracategory serial position effect to be significant $[F(4,256)=3.7, p<.01]$, and the intracategory Serial Position by List interaction to be significant $[F(4,256)=$ $4.9, \mathrm{p}<.01]$. This means that if retention is tested by recognition, performance will be better if the material is processed in anticipation of a recognition test as opposed to a recall test. In addition, the inferiority of the recall mode of processing increases with intracategory serial position when retention is tested by recognition.

Figure 3 represents the probability of recall of items as a function of intracategory serial position collapsed over categories for List 6 (stored in anticipation of a recognition test) and List 5 (stored in anticipation of a recall test) for practiced Ss. Again, the comparison of performance is made between List 5 and List 6 in order that Ss who were practiced in two different forms of encoding could be tested on a common recall test. Differences between these two functions then represent storage differences between recognition and recall modes of storage when tested by free recall. Analysis of variance of these recall data yielded no main effect $[F(1,64)<1]$, a significant intracategory serial position effect $[F(4,256)=4.0, p<.01]$, and a significant intracategory Serial Position by Storage Mode interaction $[F(4,256)=4.2, p<.01]$. These results mean that under expectations of a recall test, $\mathrm{S}$ processes the material in such a manner that difficulty of subsequent retrieval varies with intracategory serial position. On the other hand, no such serial position effects appear for material stored in anticipation of a

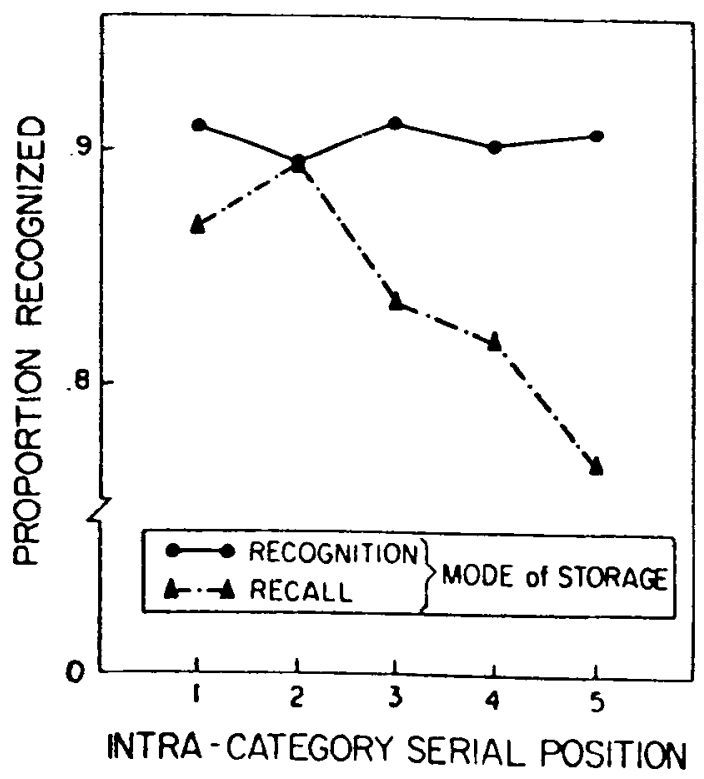

Fig. 2. Proportion of words recognized for recognition mode of storage (List 5) and recall mode of storage (List 6) as a function of intracategory serial position.

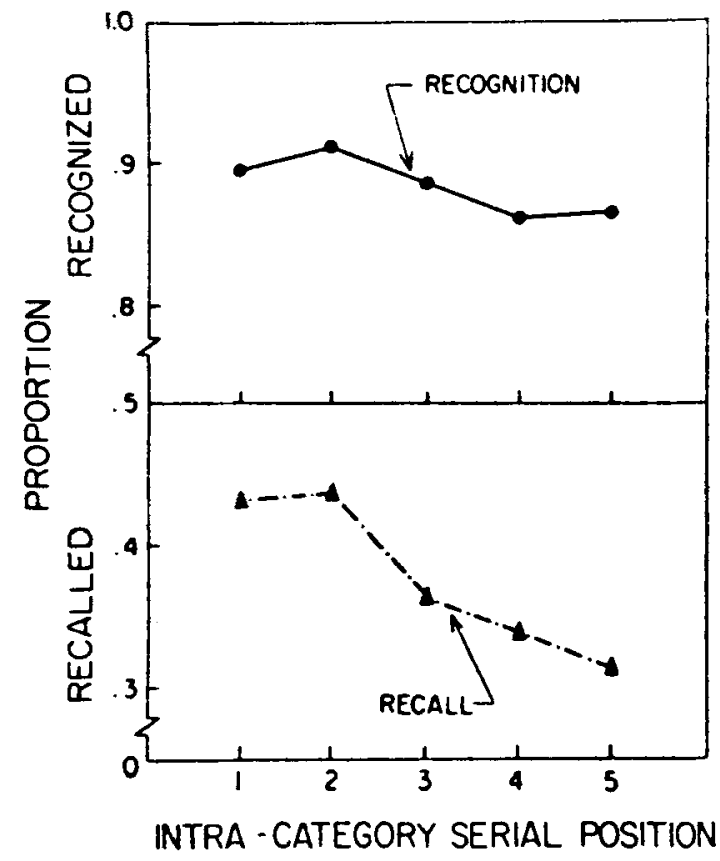

Fig. 1. Proportion of words recognized (top) or recalled (bottom) as a function of intracategory serial position collapsed over eight categories within each list and Lists 1-5.

recognition test but tested by free recall. Interpretation of the lack of a main effect for mode of processing when retention is tested by free recall must allow for the possibility that Ss practiced in recognition mode and aware of the categorized nature of the list transformed the recall test into a recognition test by retaining the category labels. Although organizational activity led to no overall advantage in recall when compared with recognition processing, the difference in storage between the two modes of processing is evident from the interaction between the intracategory serial position function and mode of processing.

Taken together, Fig. 2 and Fig. 3 argue that the anticipated form of test results in differential storage of information and this difference in storage varies significantly with intracategory serial position regardless of the form of test by which it is measured.

\section{'DISCUSSION}

This study demonstrates several findings which may have important implications for theories of recall and recognition performance. First, the data suggest that organization activities do not invariably lead to superior recognition performance; in this study organizing material in anticipation of a free recall test led to inferior recognition performance.

Second, the data suggest that the differences between recall and recognition performance for practiced Ss may be in part attributable to differences in encoding and storage and not solely attributable to retrieval differences as is often claimed (e.g., Freund, Brelsford, \& Atkinson, 1969). Clearly, the differences between 


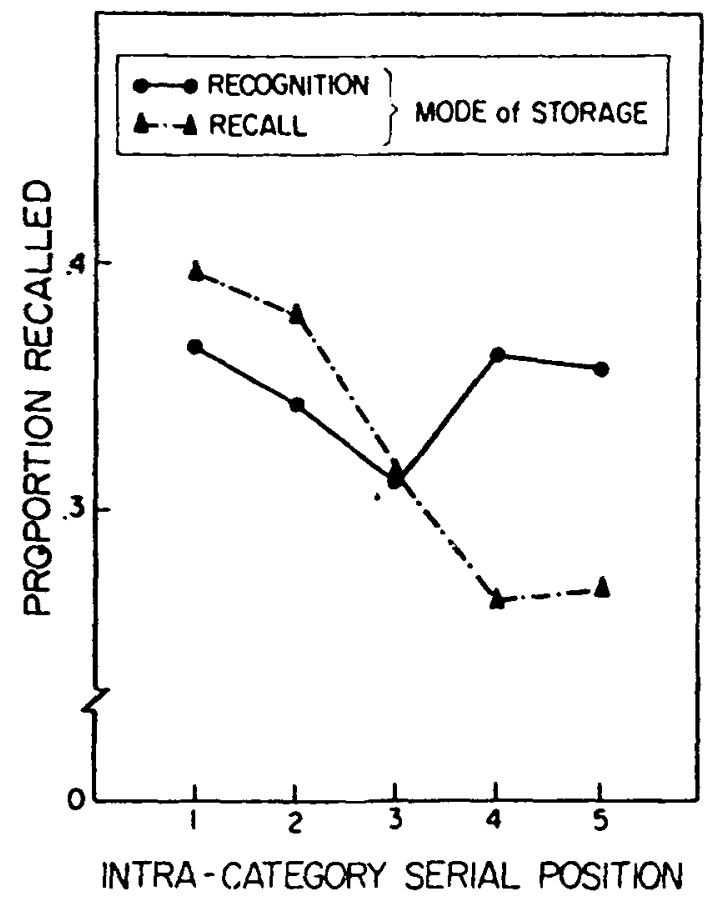

Fig. 3. Proportion of words recalled for recognition mode of storage (List 6) and recall mode of storage (List 5) as a function of intracategory serial position.

intracategory serial position functions for recall and recognition modes of encoding are suggestive evidence for differential storage between these two modes of processing. This finding is reinforced by the fact that encoding and storage differences between recall and recognition processing modes reliably appeared whether retention was tested by recognition or recall within each processing mode. This means that the manner in which a practiced $S$ encodes a given item will depend in part on the anticipated form of test. More generally, this is consistent with the viewpoint that Ss encode and store verbal material in a format that they believe will permit optimal utilization.

Previous attempts to isolate storage differences between recall and recognition modes of processing may have failed due to the minimal role that organizational processes would play in studies which employed paired-associate tasks with single letters and digits as stimuli and responses (e.g., Freund, Brelsford, \& Atkinson, 1969) and/or due to the limited practice Ss were given at developing processing modes which were optimal to the specific task demands (e.g., Loftus, 1971). The present study emphasizes the possibility that utilization of stored information should be maximal when knowledge of the functional properties of retrieval is available to $S s$ at time of encoding. These results emphasize, therefore, the need to control for possible storage effects when evidence (e.g., Mandler, 1972; Kintsch, 1968, 1970) of the influence of organization on recognition performance is discussed. Different control processes for recognition and recall processing may be one more obstacle to the direct comparison of recognition and recall performance (McCormack, 1972). If this is so, it follows that a lack of a difference in recognition performance between sets of stimulus material that differ in ease of organization cannot necessarily be used to argue for the two-stage theory of recall and recognition (e.g., Kintsch, 1970). In a similar manner, the present study raises the possibility that a difference in recognition performance between sets of stimulus material that are subjected to different amounts of organizational activities cannot necessarily be accepted as unqualified evidence for the necessity of a retrieval step in recognition. Finally, it is proposed that an analysis of intracategory serial position functions (Murdock \& Carey, 1972) may be a more sensitive index of differences in processing modes than is overall probability of retention.

\section{REFERENCES}

Atkinson, R. C., \& Shiffrin, R. M. Human memory: A proposed system and its control processes. In K. W. Spence and J. T. Spence (Eds.), The psychology of learning and motivation: Advances in research and theory. Vol. 11. New York: Academic Press, 1968. Pp. 89-195.

Battig, W. F., \& Montague, W. E. Category norms for verbal items in 56 categories: A replication and extension of the Connecticut norms. Journal of Experimental Psychology Monographs, $1969,80(3$, Pt. 2), $1-46$

Freund, R. D., Brelsford, J. W., \& A tkinson, R. C. Recognition vs. recall: Storage or retrieval differences? Quarterly Journal of Experimental Psychology, 1969, 21, 214-224.

Glanzer, M., \& Cunitz, A. R. Two storage mechanisms in free recall. Journal of Verbal Learning \& Verbal Behavior, 1966, 5, 351-360.

Kintsch, W. Recognition and free recall of organized lists. Journal of Experimental Psychology, 1968, 78, 481-487.

Kintsch, W. Learning memory and conceptual processes. New York: Wiley, 1970.

Loftus, G. R. Comparison of recognition and recall in a continuous memory task. Journal of Experimental Psychology, 1971, 91, 220-226.

Mandler, G. Organization and recognition. In E. Tulving and W. Donaldson (Eds.), Organization of memory. New York: Academic Press, 1972.

Mandler, G., \& Borges, M. A. Effects of list differentiation category membership and prior recall on recognition. Technical Report No. 16, May 1971, Center for Human Information Processing, University of California, San Diego.

McCormack, P. D. Recognition memory: How complex a retrieval system? Canadian Journal of Psychology, 1972, 26, $19-41$.

Murdock, B. B., JI., \& Carey, S. T, Release from interference in single-trial free recall. Journal of Verbal Learning \& Verbal Behavior, 1972, 11, 398-402.

Norman, D. A., \& Rumelhart, D. E. A system for perception and memory. In D. A. Norman (Ed.), Models of human memory. New York: Academic Press, 1970.

Postman, L., Jenkins, W. O., \& Postman, D. L. An experimental comparison of active recall and recognition. American Journal of Psychology, 1948, 61, 511-519.

Wood, G., \& Underwood, B. J. Implicit responses and conceptual similarity. Journal of Verbal Learning \& Verbal Behavior, $1967,6,1-10$.

(Received for publication December 27, 1972; revision received February 28, 1973.) 